\title{
Effectiveness of Mechanical Treatment for Plantar Fasciitis: A Systematic Review
}

\author{
Dorianne Schuitema, Christian Greve, Klaas Postema, Rienk Dekker, and Juha M. Hijmans
}

\begin{abstract}
Context: Plantar fasciitis is one of the most common foot injuries. Several mechanical treatment options, including shoe inserts, ankle-foot orthoses, tape, and shoes are used to relieve the symptoms of plantar fasciitis. Objectives: To investigate the effectiveness of mechanical treatment in the management of plantar fasciitis. Evidence Acquisition: The review was reported in accordance with the Preferred Reporting Items for Systematic Reviews and Meta-Analysis statement. A systematic search was performed in PubMed, CINAHL, Embase, and Cochrane up to March 8, 2018. Two independent reviewers screened eligible articles and assessed risk of bias using the Cochrane Collaboration's risk of bias tool. Evidence Synthesis: A total of 43 articles were included in the study, evaluating 2837 patients. Comparisons were made between no treatment and treatment with insoles, tape, ankle-foot orthoses including night splints and shoes. Tape, ankle-foot orthoses, and shoes were also compared with insoles. Follow-up ranged from 3 to 5 days to 12 months. Cointerventions were present in 26 studies. Conclusions: Mechanical treatment can be beneficial in relieving symptoms related to plantar fasciitis. Contoured full-length insoles are more effective in relieving symptoms related to plantar fasciitis than heel cups. Combining night splints or rocker shoes with insoles enhances improvement in pain relief and function compared with rocker shoes, night splints, or insoles alone. Taping is an effective short-term treatment. Future studies should aim to improve methodological quality using blinding, allocation concealment, avoid cointerventions, and use biomechanical measures of treatment effects.
\end{abstract}

Keywords: orthotic devices, shoes, splints, taping

Plantar fasciitis is one of the most common types of foot injuries. ${ }^{1-3}$ Approximately $10 \%$ of the general population will experience complaints associated with plantar fasciitis once in their life. ${ }^{4}$ Patients suffering from plantar fasciitis experience pain along the proximal plantar fascia and around its attachment in the area of the calcaneal tuberosity. Pain aggravates with load, as in walking and running and when first standing after a period of inactivity, such as getting out of bed in the morning. ${ }^{5}$

The exact pathology of plantar fasciitis is still unknown, but a combination of high mechanical stress and repetitive microtrauma is the one leading cause of the pathology. ${ }^{5}$ Histological findings suggest the underlying process of plantar fasciitis to be more degenerative rather than inflammatory. Therefore, the term "fasciitis" might be a misnomer and could better be replaced by "fasciosis." "Risk factors associated with plantar fasciitis are a high body mass index ${ }^{7,8}$ prolonged weight-bearing, and a limited ankle range of motion. ${ }^{9}$ In $45 \%$ to $85 \%$ of the patients suffering from plantar fasciitis, calcaneal spur is also present. ${ }^{10}$

Several nonsurgical treatment methods are available to relieve symptoms associated with plantar fasciitis. These include stretching, manual therapy, dry needling, shockwave therapy, physical agents (electrotherapy, low-level laser therapy, phonophoresis, and ultrasound), lifestyle counseling, anti-inflammatory injections, and

Schuitema and Greve are with the Center for Human Movement Sciences, University of Groningen, University Medical Center Groningen, Groningen, The Netherlands. Greve, Postema, Dekker, and Hijmans are with the Department of Rehabilitation Medicine, University of Groningen, University Medical Center Groningen, Groningen, The Netherlands. Postema is also with the Roessingh Center for Rehabilitation, Enschede, The Netherlands. Dekker is also with the Center for Sports Medicine, University of Groningen, University Medical Center Groningen, Groningen, The Netherlands. Greve (c.greve@umcg.nl) is corresponding author. mechanical treatments such as taping, rocker shoes, and (ankle-) foot orthoses ([A]FOs) including night splints. ${ }^{11}$

Mechanical treatments are promising due to the low risk of complications, good accessibility, and high capacity to relieve the mechanical load on the plantar fascia during functional tasks of daily life. The effectiveness of mechanical treatment on plantar fasciitis has previously been investigated. ${ }^{4,12-18}$ However, these studies were limited to specific mechanical devices or compared mechanical devices to nonmechanical interventions such as stretching and nonsteroidal anti-inflammatory drugs. An overview of the effectiveness of all mechanical treatment options is still missing. Therefore, the aim of this study is to provide an overview of the effectiveness of all commonly used mechanical treatment options for plantar fasciitis: taping, rocker shoes, and (A)FOs including night splints.

\section{Methods}

This review was conducted and reported according to the Preferred Reporting Items for Systematic Reviews and Meta-Analysis statement.

\section{Literature Search}

A systematic search was performed in 4 electronic databases (MEDLINE, Embase, CINAHL, and Cochrane) using a combination of Medical Subject Headings (MeSH) terms and free-text words. The exact search strategy is described in Appendix. Keywords used were plantar fasciitis, heel spur, calcaneal spur combined via a Boolean AND operator with orthotic devices, shoes, splints, rocker, soles, and tape. The search was performed up to March 26, 2017, and updated on March 8, 2018. Besides the 
database search, reference lists of all included articles were checked on additional relevant studies.

Included studies were controlled trials, focusing on treating plantar fasciitis with one or more mechanical treatment methods. In case of biomechanical or anatomical outcome measures, no control group was required. Other inclusion criteria were a minimum number of 5 participants, adult aged $(\geq 18 \mathrm{y})$, and only participants without a disease that could interfere with the symptoms of plantar fasciitis. Only primary research available in full text and written in English, Dutch, or German was included.

After removal of duplicates, 2 authors independently assessed titles, abstracts, and full text against the inclusion criteria. During title selection, articles were selected when at least one of the authors judged the paper to be included. Disagreements between the reviewers during abstract and full-text selection were resolved by discussion between the authors. If still no agreement was reached, a third author would decide.

\section{Risk of Bias}

Two authors independently assessed risk of bias using the Cochrane Collaboration's risk of bias tool. ${ }^{19}$ Risk of bias addressed in this tool include the following domains: (1) random sequence generation, (2) allocation concealment, (3) blinding of participants, (4) blinding of personnel, (5) blinding of outcome assessment, (6) incomplete outcome data, and (7) selective reporting. Other risks of bias not covered in these domains are (8) similar groups at baseline or corrected for dissimilarities; (9) cointerventions avoided of similar between groups, interventions, or measurements; (10) similar timing of outcome assessment in all groups; and (11) no conflicts of interest. All domains were judged "low risk of bias," "high risk of bias," or "unclear." In the end, studies were considered of "high risk of bias" if one or more domains were judged "high risk." If none of the domains was of "high risk" and one or more domains were "unclear," the study was assessed "unclear." If all domains were of "low risk," the overall judgment was "low risk." Disagreements between the authors were resolved in a consensus meeting. If no consensus could be reached, a third author would decide.

\section{Results}

\section{Database Search}

The database search yielded 937 articles after removal of 598 duplicates. Title screening resulted in the exclusion of 489 articles, abstract screening resulted in the exclusion of 391 articles, and in the full-text screening, another 18 articles were excluded. From those 18 articles, 2 were excluded because they were not available in full text and 16 because they did not fulfill the other inclusion criteria. Checking references of the 39 remaining articles yielded no other articles. An updated search resulted another 4 articles so in the end, 43 studies were included in the review (Figure 1).

\section{Risk of Bias}

Risk of bias assessment (Figure 2) revealed that 33 studies ${ }^{20-52}$ had one or more domains assessed as high risk of bias. For 10 studies, ${ }^{53-62}$ unclear was highest, and none of the studies scored only low risk of bias (Appendix). Greatest potential sources of high risk were blinding of personnel $(37 \%)$, blinding of outcome assessors (26\%), and cointerventions (30\%).

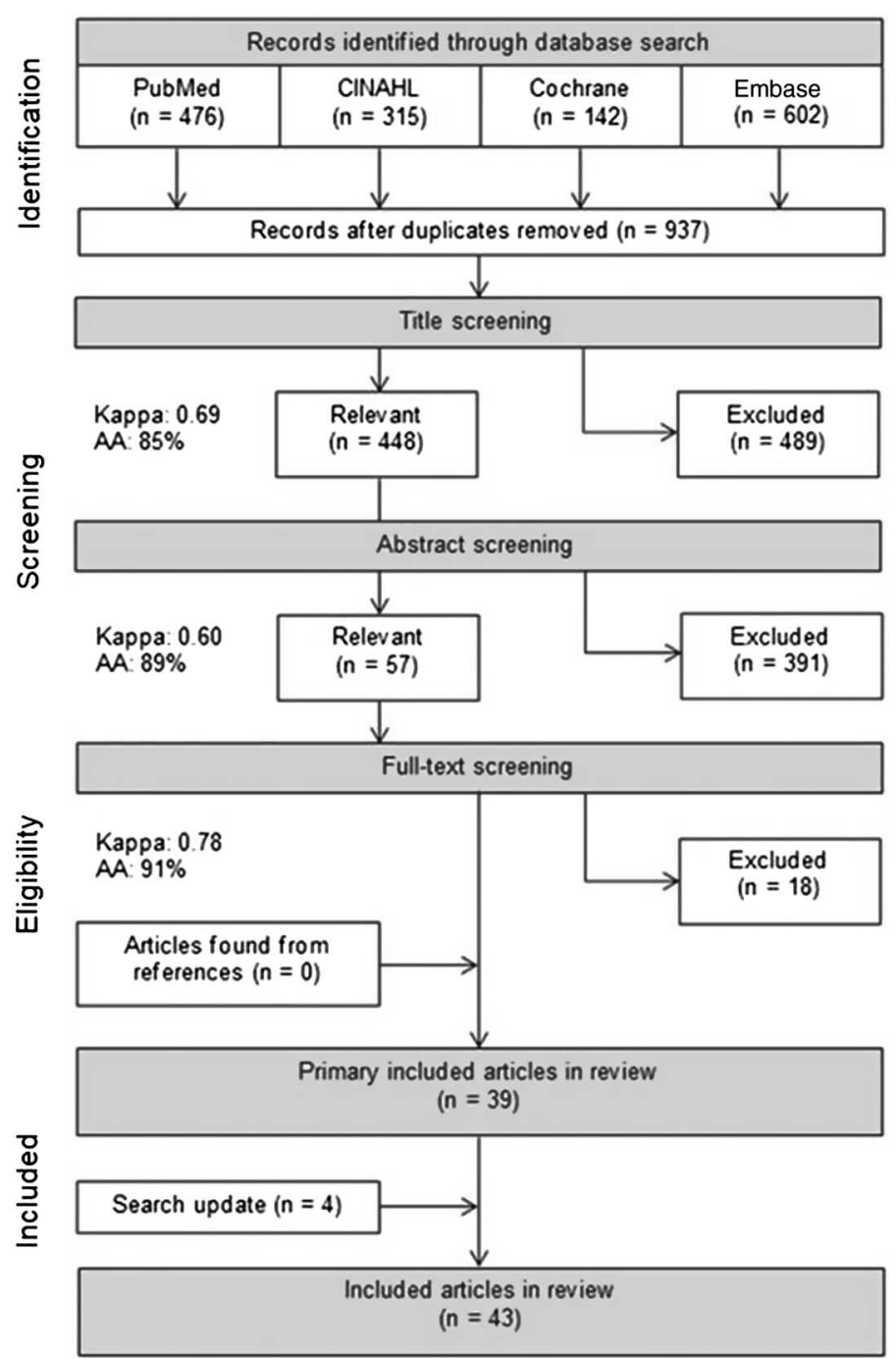

Figure 1 - Flowdiagram of the database search.

\section{Study Selection}

The 43 selected studies evaluated interventions in a total of 2837 participants. Study characteristics are shown in Table 1. All participants were diagnosed with plantar fasciitis, except for one study including patients and a control group of healthy participants. ${ }^{61}$ In almost all studies, pain scores were used as criteria for patients to participate. ${ }^{20-23,25-31,33-35,37-39,42-46,48-56,59-62}$ Four studies also evaluated plantar fascia thickness via radiologic evaluation. ${ }^{27,44,45,48}$ Patients who had undergone foot surgery or previous treatment for plantar fasciitis were excluded in 27 out of 43 studies. ${ }^{21,23,25-31,33-35,38,42,43,46,48,51-56,59-62}$

\section{Interventions}

All studies evaluated one or more mechanical interventions for plantar fasciitis. The most studied intervention was the insole. Seventeen studies $24,27-30,35,41,43,44,46,48-51,54,59,62$ compared insoles to another type of insole, no insole, or to a nonmechanical treatment method. Nine studies focused on taping, ${ }^{23,34,40,52,55-58,61} 7$ studies on night splints, ${ }^{25,31-33,39,45,47} 2$ studies on daytime worn AFOs, ${ }^{20,38}$ and 3 studies on shoes. ${ }^{37,42,51}$ Comparisons were also 


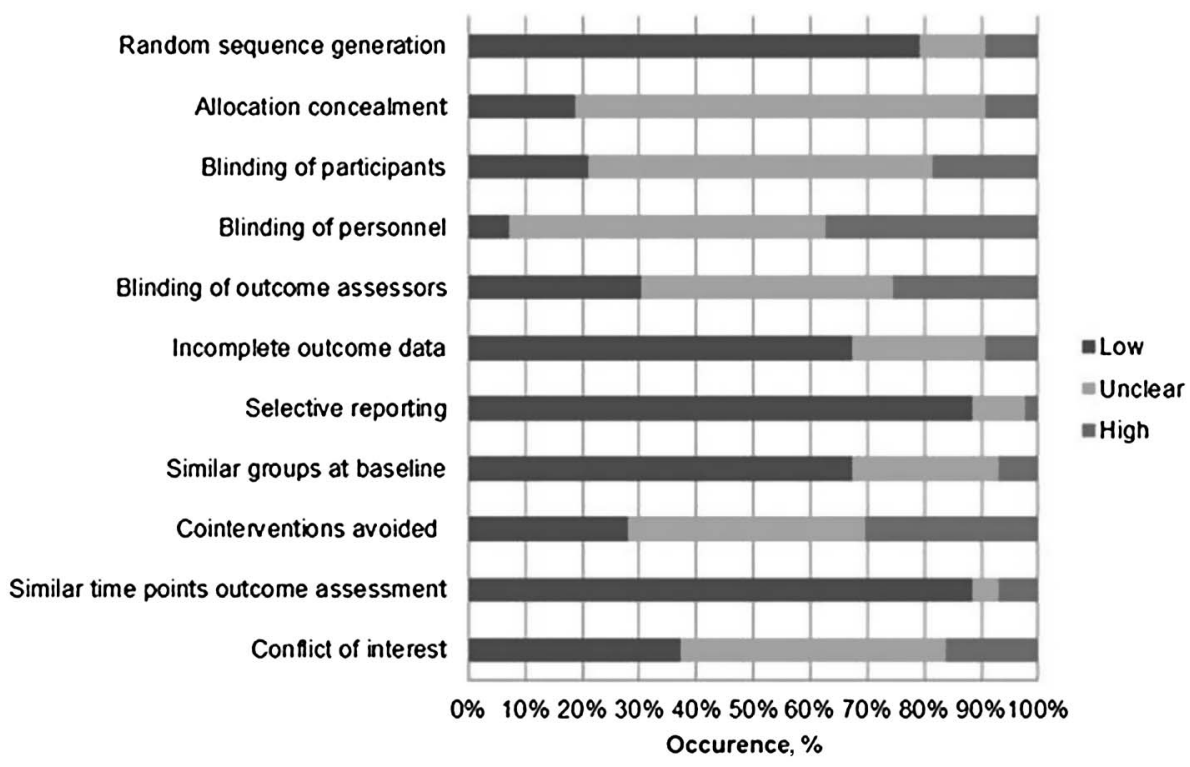

Figure 2 - Risk of bias assessment.

made between different types of mechanical treatment. Five studies were conducted at a single visit. ${ }^{48,51,54,60,61}$ Follow-up of the other studies ranged from 3 to 5 days to 12 months.

In some studies, participants used more treatments than just the treatment being examined. These additional treatments were applied to all participants in 20 studies $^{20,22,23,25,27,30,33,37-41,45-47,53,57-59}$ and only by part of all participants in 11 studies. ${ }^{26-29,36,38,41,43,46,50,62}$

\section{Effect of Interventions}

Outcomes of the included studies are shown in Tables 2 and 3. Based on previous research, minimal clinically important differences were $9 \mathrm{~mm}$ for the visual analog scale, 12 for the Foot Function Index (FFI)_pain, 7 for Foot Function Index-disability, 7 for Foot Function Index - total, 14 for the Foot Health Status Questionnaire —pain, and 7 for Foot Health Status Questionnaire-function. ${ }^{63}$

\section{Insoles}

The most studied intervention in the included articles was insoles. Comparisons were made between insole and no-insole use, between prefabricated and customized insoles, and between fulllength insoles and heel cups.

Of the 25 studies $^{21,22,24-30,35,36,41-44,46,48-51,53,54,59,60,62}$ investigating the effect of insoles on plantar fasciitis, 10 studies $24,26,29,30,44,46,48,49,51,54,62$ included a control group wearing no insole or a sham orthosis or receiving nonmechanical interventions. Three studies ${ }^{29,44,51}$ reported significantly lower pain scores after insole use compared with the control group; one study ${ }^{62}$ found significantly lower pain scores in the control group receiving a corticosteroid injection, and 5 other studies ${ }^{24,26,30,46,49}$ found no significant differences in pain between insole and control. Improvement in function differed significant between insoles and control in 2 out of 5 studies. One study ${ }^{24}$ favored insoles over sham insoles, and another study ${ }^{62}$ favored corticosteroid injections over insoles. Biomechanical analysis has been done in 7 studies. ${ }^{29,44,46,48,51,54,62}$ Two studies $^{29,51}$ found a significantly larger contact area and significantly lower plantar pressure when wearing full-length insoles compared with no insoles, but 2 others found no significant differences.
Prefabricated Versus Customized Insoles. Six studies $24,30,35,43,46,48$ focused on differences between prefabricated and customized insoles. Function was assessed in 4 studies. ${ }^{24,35,43,46}$ Two studies ${ }^{24,35}$ reported an improvement after both prefabricated and customized insole use, whereas the participants in 2 other studies ${ }^{43,46}$ remained at the same function level. None of the included studies found significant differences between both types of insoles. Comparable results were found for pain. Both prefabricated and customized insoles caused a pain decrease in all 4 studies evaluating pain, but again, no significant differences were found between both groups. ${ }^{24,30,43,46}$ Significant differences between prefabricated and customized insoles were only found for walking distance, with the customized insole being more effective than the prefabricated insole.

Heel Pads Versus Full-Length Insoles. Effects of full-length insoles and heel pads were evaluated in 4 studies. ${ }^{27,41,48,54}$ One study found full-length insoles being more effective in pain reduction than heel cups, ${ }^{27}$ but in another study, no significant differences between both interventions were found for pain and function. ${ }^{41}$ Biomechanical outcomes were assessed in 2 crossover studies. ${ }^{48,54}$ Both studies found significantly lowered heel pressure when wearing a full insole, one study found a significantly larger contact during full-length insole use. ${ }^{54}$

Other Insoles. Two studies ${ }^{50,59}$ compared different types of fulllength insoles. One assessed satisfaction of a homogenous and heterogeneous thermoplastic orthosis ${ }^{50}$ but did not find a significant difference. The other one compared accommodative and functional insoles. ${ }^{59}$ Improvements were seen in pain in both groups, but function and quality of life was improved only in the functional insole group. It is unclear whether differences between groups were significant.

\section{Shoes}

Shoe adaptations were evaluated in 3 studies. ${ }^{37,42,51}$ Fong et al ${ }^{51}$ performed a crossover study with a normal shoe, a rocker shoe, and a flat and customized insole. Pain scores were significantly lowered with both rocker shoe conditions and with a normal shoe combined with a customized insole. Rocker shoe combined with customized 


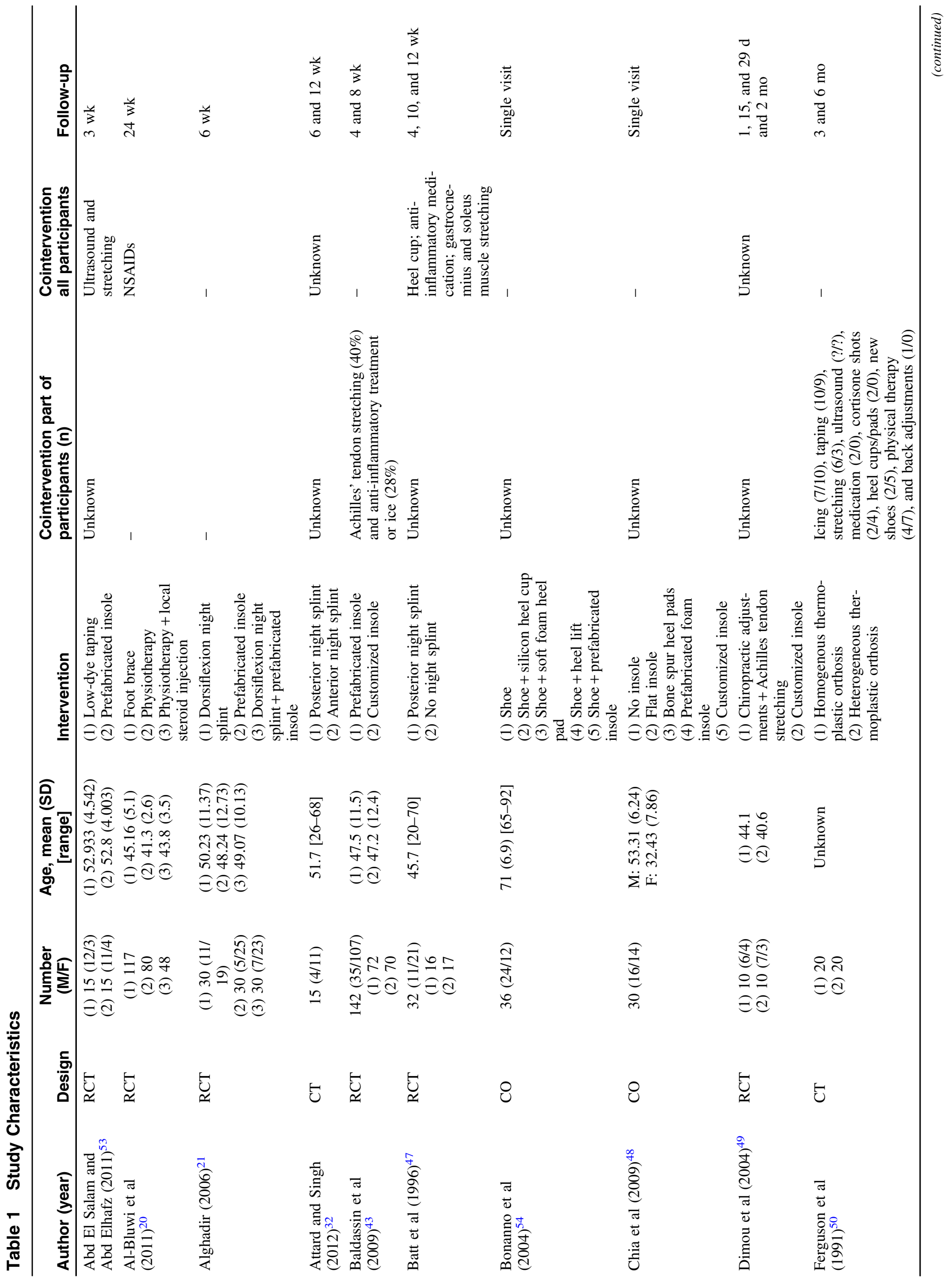




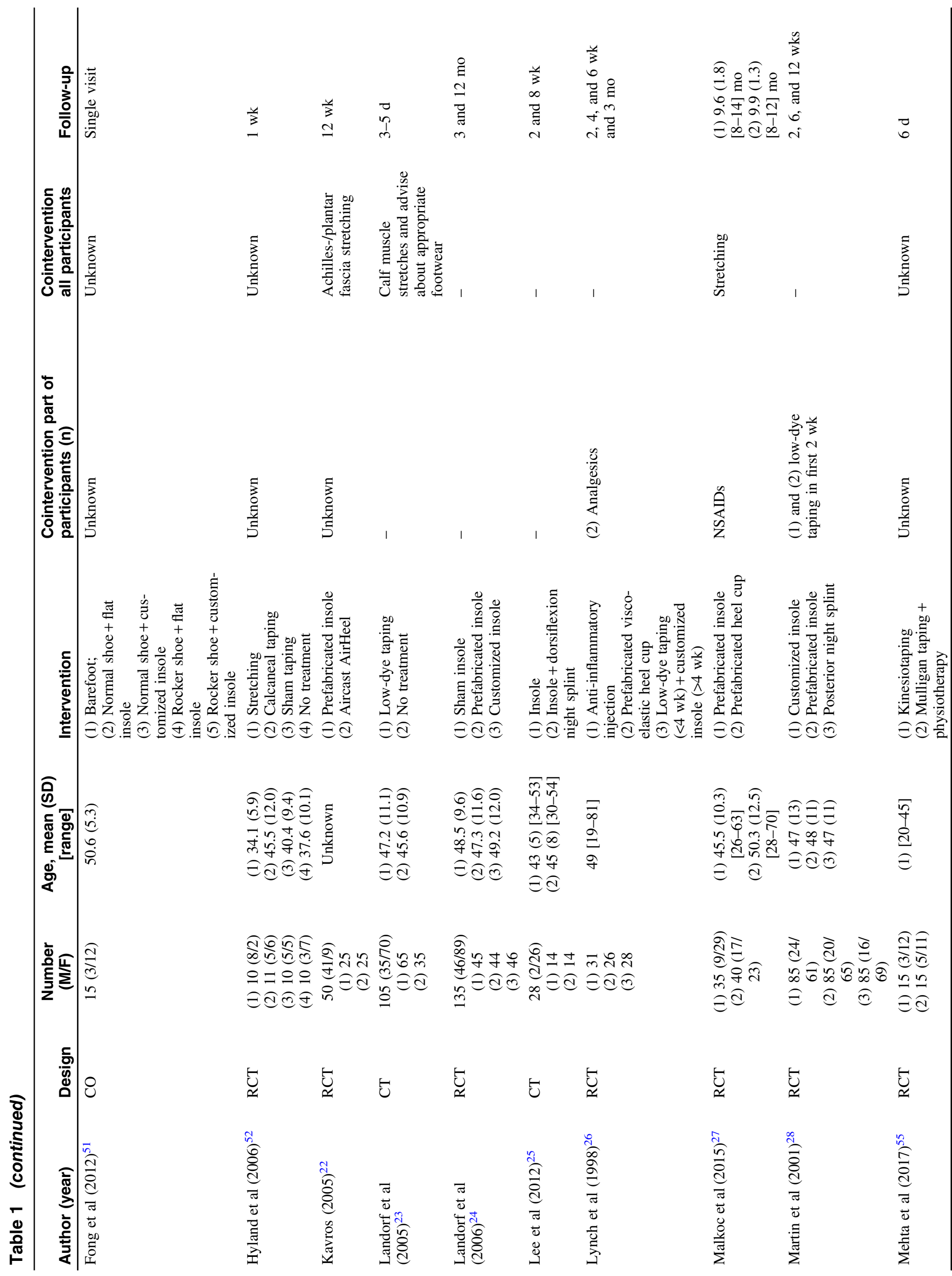




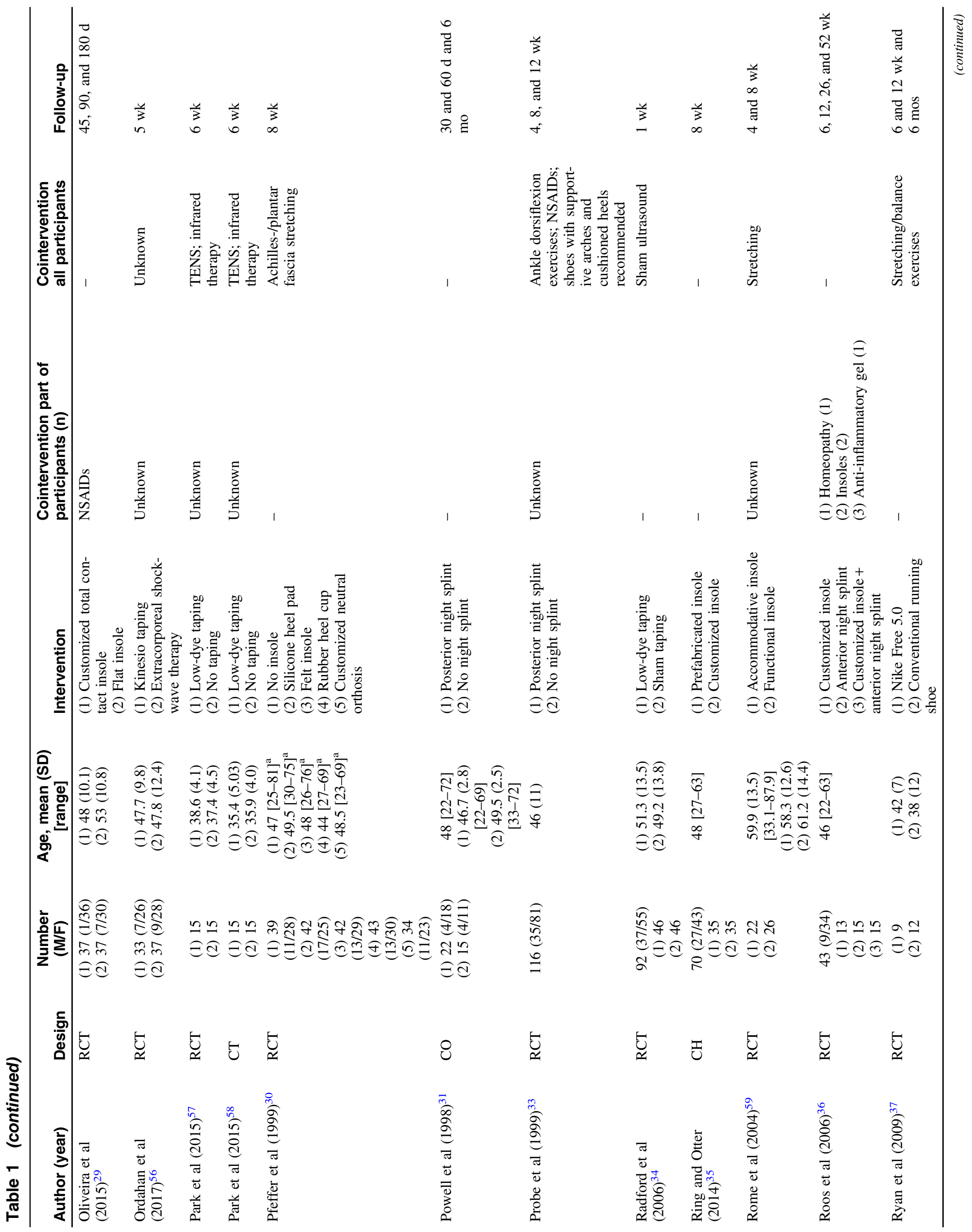




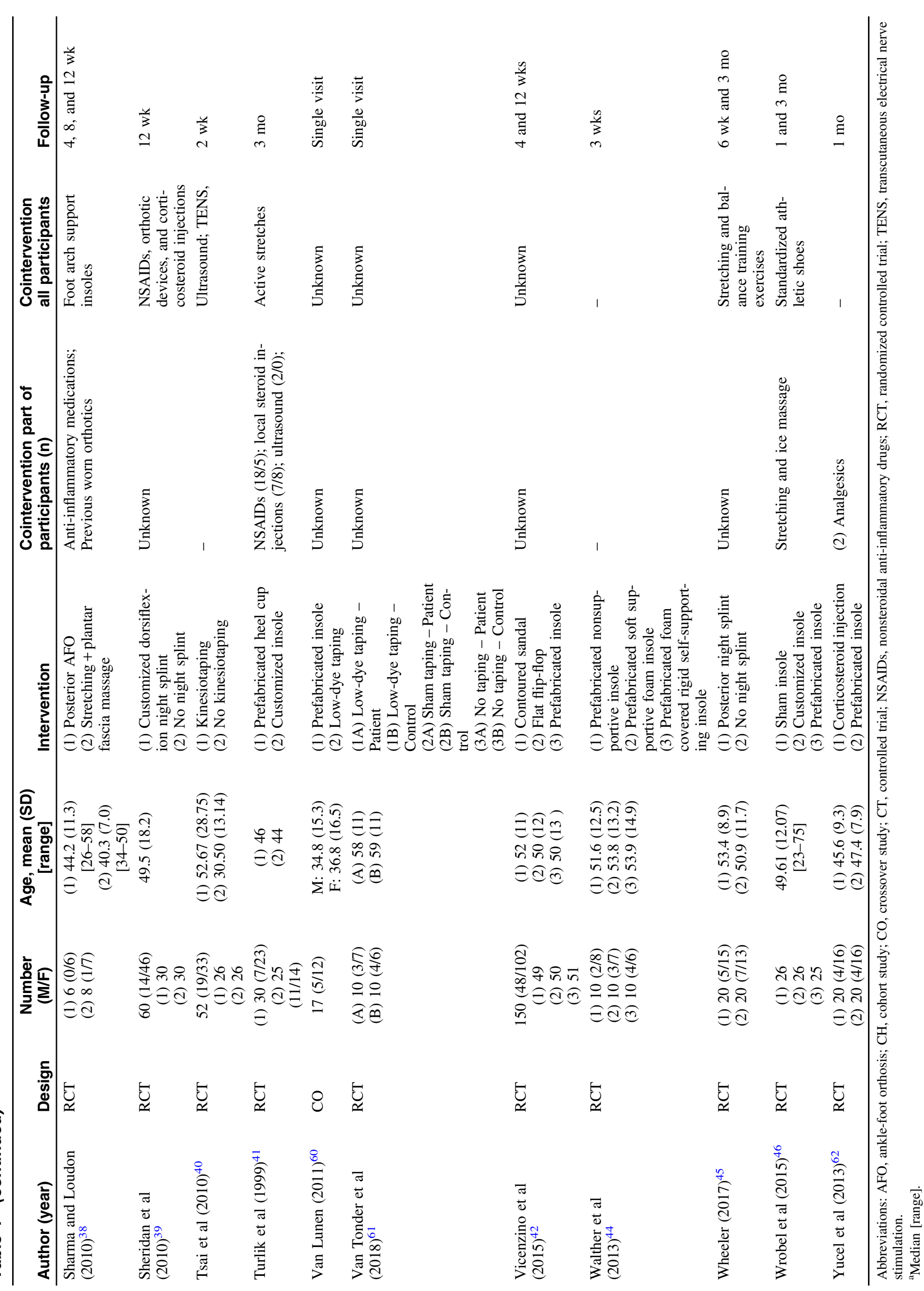




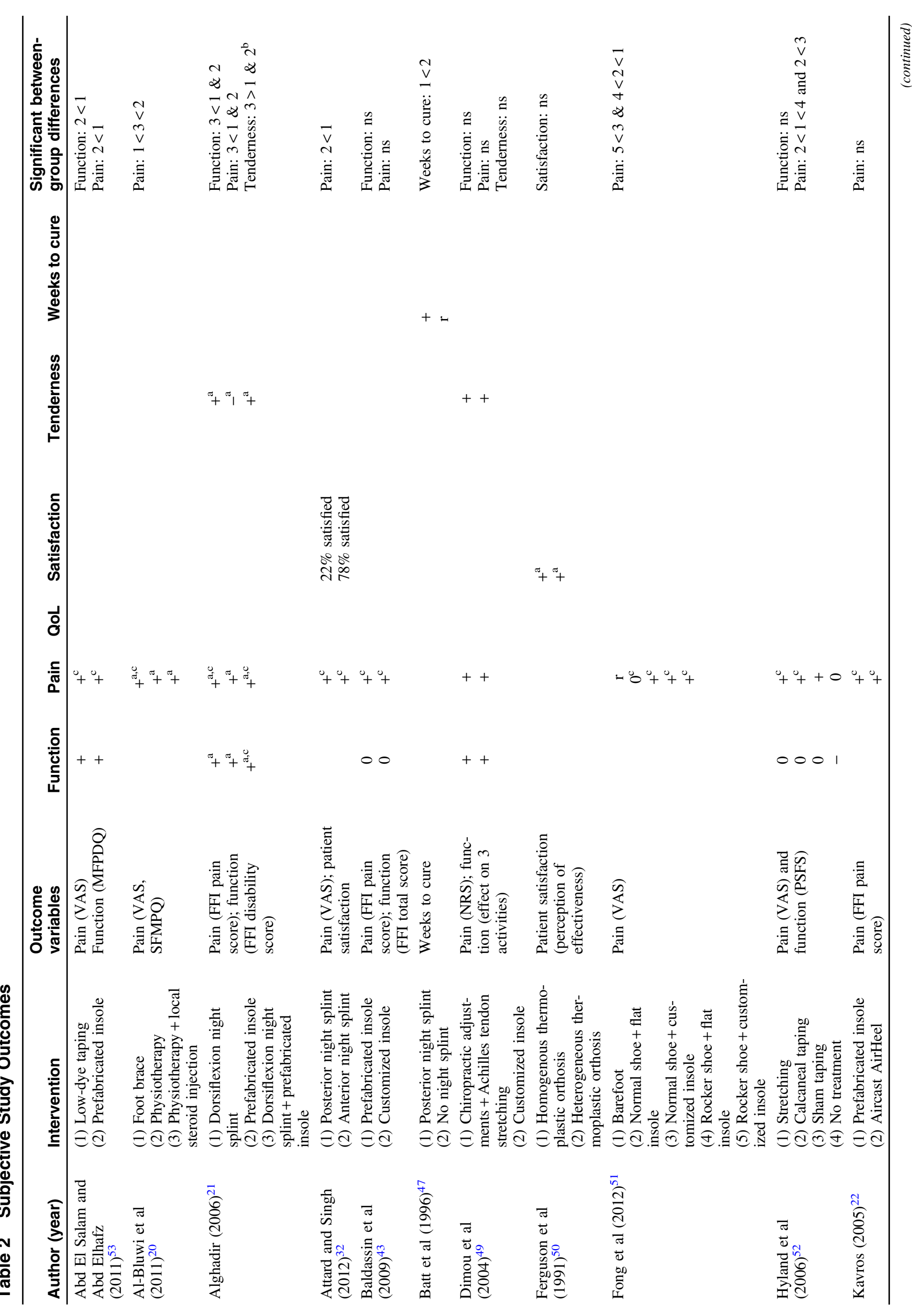




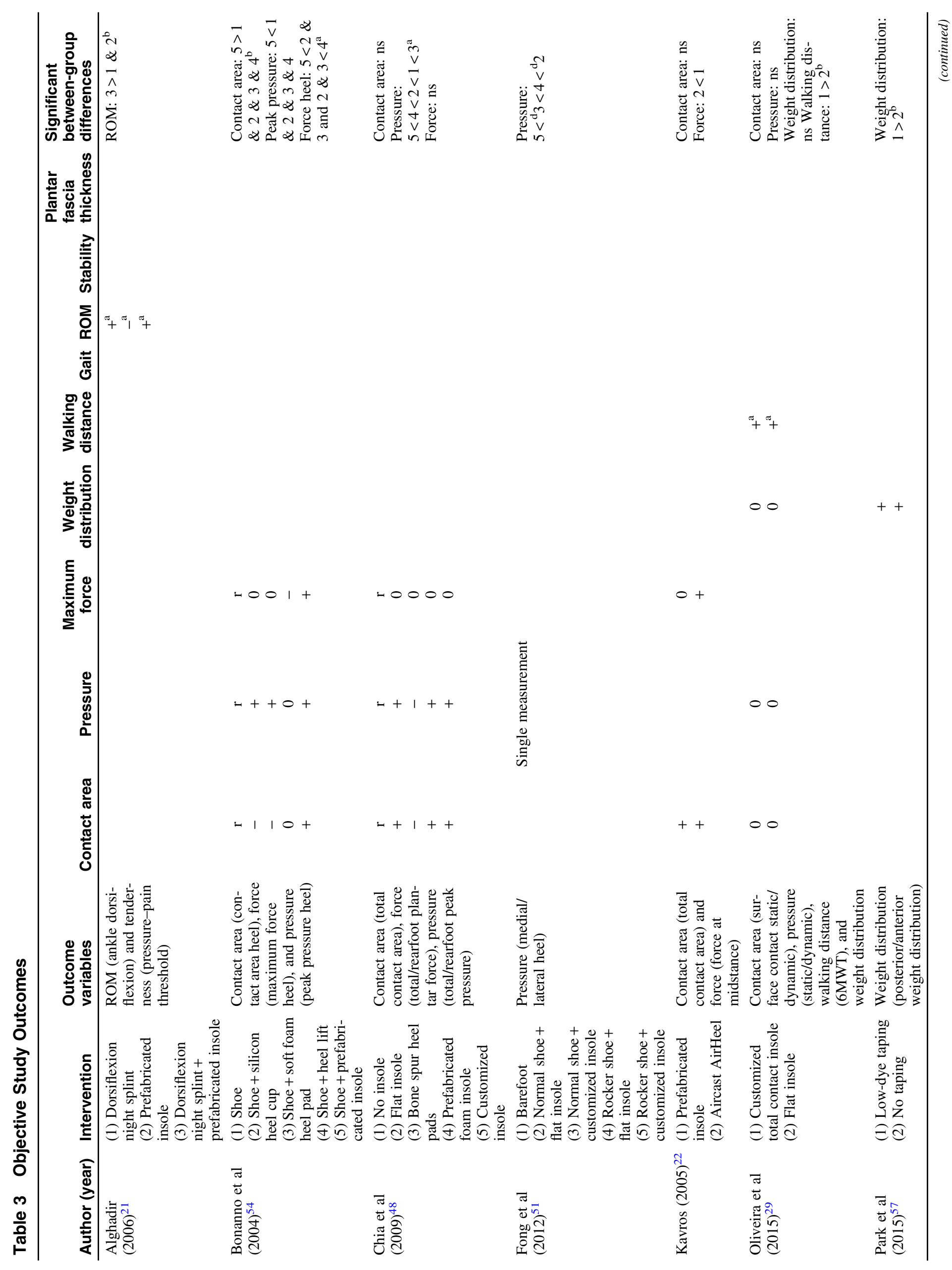


insole was best in relieving pressure followed by normal shoe combined with customized insole and rocker shoe combined with flat insole. No improvement in function was observed for flat flipflops, prefabricated insoles and sandals having contours such as the insole, but contoured sandals were more effective in pain reduction than flat flip-flops. ${ }^{42}$

\section{Ankle-Foot Orthoses}

Three studies ${ }^{20,22,38}$ examined the effect of daytime worn AFOs on plantar fasciitis. Two compared ${ }^{20,38}$ AFOs with nonmechanical treatments. No significant differences in function were found. ${ }^{38}$ One study ${ }^{20}$ did find a significant differences in pain, with the AFO being more effective, but another study ${ }^{38}$ did not.

One study ${ }^{22}$ compared an AFO with a prefabricated insole. No significant differences in pain and contact area were found. Plantar force was significantly lowered in the AFO group.

\section{Night Splints}

Ankle-foot orthoses worn at night were evaluated in 10 articles. $^{21,25,28,31-33,36,39,45,47}$ Five $^{31,33,39,45,47}$ studied patients with and without a night splint. Four ${ }^{31,33,39,45}$ of them assessed pain and 2 found significantly lower pain scores after night splint use. ${ }^{31,39}$ Function was improved after night splint use in 1 out of 2 studies. $^{31}$ The other one $^{33}$ did not find a significant difference with or without night splints. A distinction was made between anterior and posterior night splints in one study. Participants wearing the anterior night splint were more satisfied compared with posterior night splint users. ${ }^{32}$

\section{Night Splints Versus Insoles}

Four studies $21,25,28,36$ compared night splints with insoles. There were no significant differences in pain, ${ }^{21,28}$ function, ${ }^{21,36}$ quality of life, ${ }^{36}$ ankle dorsiflexion, and heel tenderness ${ }^{21}$ between night splint or insole use, but combining night splints and insoles did lead to improvement in pain, function, ${ }^{21,25}$ ankle dorsiflexion, and heel tenderness. ${ }^{21}$ One study reported a different result and found significantly lower pain scores after insole use compared with night splint and night splint + insole. Night splint and night splint + insole did not differ significantly. ${ }^{36}$

\section{Taping}

A total of 12 studies $23,26,34,40,52,53,55-58,60,61$ investigated the effect of taping on plantar fasciitis. Eight studies $23,26,34,53,57,58,60,61$ used low-dye tape. Other taping techniques used were kinesiotaping, ${ }^{40,55,56}$ calcaneal taping, ${ }^{52}$ and Mulligan taping. ${ }^{55}$

Seven studies $23,34,40,52,57,58,61$ compared taping with no treatment or sham taping. Of these studies, 6 studies $^{23,40,52,58,61,64}$ had pain as an outcome measure, and they all reported a significant decrease in pain in the taping group. Four studies ${ }^{34,40,52,58}$ also reported a significant pain reduction in the control group, but all favored taping over no taping or sham taping. Function did not differ significantly between taping and no taping, ${ }^{34,52}$ but taping was most effective regarding to weight distribution, ${ }^{57}$ stability, ${ }^{58}$ and plantar fascia thickness. ${ }^{40}$

\section{Taping Versus Insoles}

Three studies ${ }^{26,53,60}$ compared low-dye taping to insoles. All observed a decrease in pain in both taping and insole groups; 2 studies $^{26,53}$ found a significant difference between both interventions, with the insole being more effective in reducing pain than tape. Insoles were also found to be more effective in improving function, ${ }^{53}$ whereas tape led to significantly lower mean plantar pressure. ${ }^{60}$

\section{Discussion}

The aim of this study was to systematically review the effects of insoles, AFOs, shoes, and tape as treatment for plantar fasciitis. In total, 43 studies were included, evaluating 2837 patients. Treating plantar fasciitis mechanically seems to be beneficial in relieving symptoms related to plantar fasciitis. None of the included studies reported a negative effect of mechanical treatment; all were reporting a positive or no effect.

Of all included studies, the most investigated treatment was insoles. Insoles in different shapes and materials are used to treat plantar fasciitis. Insoles covering the whole foot have a larger area of contact between the insole and the foot compared with heel cups. A larger contact area improves pressure distribution under the foot and therefore minimizes peak pressures at the insertion of the plantar fascia. ${ }^{48,54}$ Moreover, insoles having contours support the longitudinal arch, which is associated with less plantar fascia strain. ${ }^{65}$ However, despite the biomechanical differences between full-length insoles and heel cups, only one ${ }^{41}$ out of 3 studies reported a significantly larger pain decrease after full-length insole use compared with heel cups. The other 2 studies ${ }^{27,30}$ did not report significant differences between both shoe inserts. Furthermore, the effectiveness of prefabricated insoles on pain relief was compared with customized insoles. Because customized insoles are individually adapted to the anatomy of a person's foot, we expected favorable effects of customized insoles. However, pain and function scores were comparable between prefabricated and customized insoles. ${ }^{24,30,35,43,46}$

As an alternative to insoles, shoe adaptations might be used to relieve symptoms associated with plantar fasciitis. A commonly used adaptation is a rocker-soled shoe with a stiff insole and proximal apex position. A more proximal apex position facilitates early heelrise and therefore minimizes external plantar flexion moments and plantar forefoot pressure. Lower plantar flexion moments require less pulling forces of the Achilles tendon, which leads to a smaller plantar fascia strain during gait. ${ }^{66-69} \mathrm{~A}$ proximal apex position in combination with a stiff insole further minimizes plantar fascia strain by preventing excessive bending of the metatarsophalangeal joints (MTP joints).$^{70-72}$ In line with this proposed biomechanical effects of rocker shoes, lowered pain scores were found after the use of rocker shoes. Interestingly, prescribing rocker shoes combined with contoured insoles led to an even larger pain reduction. ${ }^{51}$ According to the authors, this was due to the pressure distributing properties of the insole. However, the contoured insoles were stiffer than the flat insoles, so the extra stiffness of the contoured insole might have an additional effect on minimizing MTP dorsiflexion leading to larger pain reductions compared with rocker shoes with flat insoles. Contoured sandals also seem to have a positive effect on pain related to plantar fasciitis. However, evidence about shoe adaptations is limited, and more research is needed to evaluate the effects of shoe sole design on plantar fasciitis.

Although rocker shoes aim to relieve pain symptoms and promote healing processes by reducing plantar fascia strain during gait, the purpose of AFOs is to increase tension on the plantar fascia during rest. During sleep, the plantar fascia is in a shortened and nonfunctional state. ${ }^{47}$ Through slight dorsiflexion at the ankle joint with an AFO, the plantar fascia remains in a lengthened state, and weight-bearing in the morning can better be tolerated by the 
patient. ${ }^{73}$ In addition, slight tension of the plantar fascia during sleep is hypothesized to promote plantar fascia healing. ${ }^{47}$ Although the evaluated AFOs differ in design (posterior vs anterior) and time of wearing (day vs night), all had a positive effect on pain and function. Anterior night splints were found to be more comfortable and more effective in pain reduction than posterior night splints, but evidence is weak, as only one study included both types of night splints. ${ }^{32}$ The investigated anterior AFO maintained the ankle angle at $90^{\circ}$, whereas the posterior AFO positioned the ankle in slight dorsiflexion. More ankle dorsiflexion increases tension on the plantar fascia through the pulling force of the Achilles tendon, possibly leading to more discomfort for the patient. AFOs seem to be as effective as insoles or stretching, but combining night splints and insoles led to enhanced improvements in pain and function compared with wearing night splints or insoles alone.

The previously mentioned treatment options were mostly prescribed for a longer period of time ( $>1 \mathrm{mo}$ ). Taping is mainly used in the short term $(<1 \mathrm{mo})$ to improve biomechanics of the foot. ${ }^{52,64,73}$ Several taping techniques were used in the included studies, but all resulted in improvements in pain and function. It is unclear whether tape or insoles are more effective in reducing plantar fascia complaints. Abd El Salam and Abd Elhafz ${ }^{53}$ favored insoles over tape, whereas Lynch et $\mathrm{al}^{26}$ reported the opposite and favored tape over insoles and Van Lunen et $\mathrm{al}^{60}$ did not find significant differences between both interventions. Several reasons might be responsible for these contradictory findings. In the study of Lynch et al, ${ }^{26}$ participants received tape in the first 4 weeks of treatment and then used an insole. However, the contribution of each of the interventions to the reported decrease in pain is unclear. Van Lunen et $\mathrm{al}^{60}$ measured participants once, whereas the others had multiple follow-up sessions ranging over a few weeks. ${ }^{26,53}$ Van Lunen et al ${ }^{60}$ found significantly lowered rearfoot mean peak pressure in patients receiving tape but no significant difference in pain scores between tape and insoles. A lowered mean peak pressure might be beneficial in treating plantar fasciitis but maybe only in the long term. If so, it is not surprising that no significant differences in pain scores were visible during that single measurement.

Methodological differences such as outcome measures, follow-up time, and treatment design limit comparability between studies. Therefore, we could not conclude which treatment is most effective in relieving symptoms associated with plantar fasciitis. In addition, risk of bias was moderate to high in all included studies requiring cautious interpretation of the obtained results. Largest contributors to a high risk of bias were lack of blinding, unclear allocation concealment, and use of cointerventions. Especially, the use of cointerventions limits interpretability of the current study outcomes. For example, insoles have a beneficial effect on pain and function and their use as cointervention most likely affects overall treatment outcomes. In addition, the application of cointerventions was inconsistent and poorly reported. In some studies, additional treatment was provided to all participants, some only to a part and others did not explicitly say whether they allowed additional treatment or not. Future studies should avoid cointerventions or investigate their interaction with the primary intervention to improve interpretability of treatment outcomes.

Furthermore, we want to note that less than half of all studies used objective measures such as foot pressure to evaluate mechanical treatment effects. Mechanical treatments aim to modify biomechanical characteristics of the foot such as plantar pressure distribution in insoles or plantar fascia length in rocker shoes and AFOs. To judge the effectiveness of these mechanical treatments, their biomechanical effects should be evaluated in addition to measures of pain and foot function. For example, musculoskeletal models could be used to establish the effect of rocker shoes on plantar fascia strain during gait in patients with plantar fasciitis. ${ }^{72}$ Information on the biomechanical treatment effects can, in turn, be used to understand and improve the effectiveness of mechanical treatments.

\section{Conclusions}

Mechanical treatment seems to be beneficial in relieving symptoms related to plantar fasciitis. Methodological limitations of current studies do not allow to conclude whether any of the investigated treatments is more effective in relieving pain or improving foot function in patients with plantar fasciitis. Combining different treatment modalities such as AFOs and insoles or rocker shoes and insoles seems to enhance clinically relevant treatment effects. Future studies should aim to improve methodological quality using blinding, allocation concealment, avoid cointerventions, and use biomechanical measures of treatment effects.

\section{Acknowledgment}

This work was supported by OIM Orthopedie, Assen, The Netherlands.

\section{References}

1. Buchbinder R. Plantar fasciitis. N Engl J Med. 2004;350(21):21592166. PubMed ID: 15152061 doi:10.1056/NEJMcp032745

2. Lopes AD, Hespanhol LC, Yeung SS, Costa LOP. What are the main running-related musculoskeletal injuries? Sports Med. 2012;42(10): 891-905. PubMed ID: 22827721 doi:10.1007/BF03262301

3. Taunton JE, Ryan MB, Clement DB, McKenzie DC, Lloyd-Smith DR, Zumbo BD. A retrospective case-control analysis of 2002 running injuries. Br J Sports Med. 2002;36(2):95-101. PubMed ID: 11916889 doi:10.1136/bjsm.36.2.95

4. Crawford $\mathrm{F}$, Thomson CE. Interventions for treating plantar heel pain. Cochrane Database Syst Rev. 2003;3:CD000416. doi:10.1002/ 14651858.CD000416

5. Cutts S, Obi N, Pasapula C, Chan W. Plantar fasciitis. Ann $R$ Coll Surg Engl. 2012;94(8):539-542. PubMed ID: 23131221 doi:10. 1308/003588412X13171221592456

6. Lemont H, Ammirati KM, Usen N. Plantar fasciitis: a degenerative process (fasciosis) without inflammation. J Am Podiatr Med Assoc. 2003; 93(3):234-237. PubMed ID: 12756315 doi:10.7547/87507315-93-3-234

7. Rano JA, Fallat LM, Savoy-Moore RT. Correlation of heel pain with body mass index and other characteristics of heel pain. J Foot Ankle Surg Off Publ Am Coll Foot Ankle Surg. 2001;40(6):351-356. doi:10. 1016/S1067-2516(01)80002-8

8. van Leeuwen KDB, Rogers J, Winzenberg T, van Middelkoop M. Higher body mass index is associated with plantar fasciopathy/ 'plantar fasciitis': systematic review and meta-analysis of various clinical and imaging risk factors. Br J Sports Med. 2016;50(16):972981. PubMed ID: 26644427 doi:10.1136/bjsports-2015-094695

9. Riddle DL, Pulisic M, Pidcoe P, Johnson RE. Risk factors for plantar fasciitis: a matched case-control Study. J Bone Joint Surg Am. 2003; 85(5):872-877. PubMed ID: 12728038 doi:10.2106/00004623200305000-00015

10. Kirkpatrick J, Yassaie O, Mirjalili SA. The plantar calcaneal spur: a review of anatomy, histology, etiology and key associations. J Anat. 2017;230(6):743-751. PubMed ID: 28369929 doi:10.1111/joa. 12607

11. Martin RL, Davenport TE, Reischl SF, et al. Heel pain-plantar fasciitis: revision 2014. J Orthop Sports Phys Ther. 2014;44(11): A1-A33. PubMed ID: 25361863 doi:10.2519/jospt.2014.0303 
12. Hawke F, Burns J, Radford J, du Toit V. Custom foot orthoses for the treatment of foot pain: a systematic review. J Foot Ankle Res. 2008;1(1):O46. doi:10.1186/1757-1146-1-S1-O46

13. Landorf KB. Plantar heel pain and plantar fasciitis. BMJ Clin Evid. 2015;2015:1111. PubMed ID: 26609884

14. Lee SY, McKeon P, Hertel J. Does the use of orthoses improve selfreported pain and function measures in patients with plantar fasciitis? A meta-analysis. Phys Ther Sport. 2009;10(1):12-18. PubMed ID: 19218074 doi:10.1016/j.ptsp.2008.09.002

15. Podolsky R, Kalichman L. Taping for plantar fasciitis. J Back Musculoskelet Rehabil. 2015;28(1):1-6. PubMed ID: 24867905 doi:10.3233/BMR-140485

16. van de Water ATM, Speksnijder CM. Efficacy of taping for the treatment of plantar fasciosis. J Am Podiatr Med Assoc. 2010; 100(1):41-51. PubMed ID: 20093544 doi:10.7547/1000041

17. Whittaker GA, Munteanu SE, Menz HB, Tan JM, Rabusin CL, Landorf KB. Foot orthoses for plantar heel pain: a systematic review and meta-analysis. Br J Sports Med. 2018;52(5):322-328. PubMed ID: 28935689 doi:10.1136/bjsports-2016-097355

18. Salvioli S, Guidi M, Marcotulli G. The effectiveness of conservative, non-pharmacological treatment, of plantar heel pain: a systematic review with meta-analysis. Foot. 2017;33:57-67. doi:10.1016/j.foot. 2017.05.004

19. Higgins JPT, Altman DG, Sterne JAC. Chapter 8: Assessing risk of bias in included studies. In: Higgins J, Churchill R, Chandler J, Cumpston M, eds. Cochrane Handbook for Systematic Reviews of Interventions. Version 5.2.0. (updated June 2017), Cochrane; 2017.

20. Al-Bluwi MT, Sadat-Ali M, Al-Habdan IM, Azam MQ. Efficacy of EZStep in the management of plantar fasciitis: a prospective, randomized study. Foot Ankle Spec. 2011;4(4):218-221. PubMed ID: 21868794 doi:10.1177/1938640011407318

21. Alghadir AH. Conservative Treatment of Plantar Fasciitis with Dorsiflexion Night Splints and Medial Arch Supports: A Prospective Randomized Study [PhD thesis]. University of Pittsburgh; 2006.

22. Kavros SJ. The efficacy of a pneumatic compression device in the treatment of plantar fasciitis. J Appl Biomech. 2005;21(4):404-413. PubMed ID: 16498185 doi:10.1123/jab.21.4.404

23. Landorf KB, Radford JA, Keenan AM, Redmond AC. Effectiveness of low-dye taping for the short-term management of plantar fasciitis. $J$ Am Podiatr Med Assoc. 2005;95(6):525-530. PubMed ID: 16291843 doi:10.7547/0950525

24. Landorf KB, Keenan AM, Herbert RD. Effectiveness of foot orthoses to treat plantar fasciitis: a randomized trial. Arch Intern Med. 2006;166(12):1305-1310. PubMed ID: 16801514 doi:10.1001/ archinte.166.12.1305

25. Lee WC, Wong WY, Kung E, Leung AK. Effectiveness of adjustable dorsiflexion night splint in combination with accommodative foot orthosis on plantar fasciitis. J Rehabil Res Dev. 2012;49(10): 1557-1564. PubMed ID: 23516059 doi:10.1682/JRRD.2011.09.0181

26. Lynch DM, Goforth WP, Martin JE, Odom RD, Preece CK, Kotter MW. Conservative treatment of plantar fasciitis. A prospective study. J Am Podiatr Med Assoc. 1998;88(8):375-380. PubMed ID: 9735623 doi:10.7547/87507315-88-8-375

27. Malkoc M, Korkmaz O, Kara A, Oltulu I, Say F. Comparison of medial arch-supporting insoles and heel pads in the treatment of plantar fasciitis. Serbian J Exp Clin Res. 2015;16(1):39-42. doi:10. 1515/sjecr-2015-0006

28. Martin JE, Hosch JC, Goforth WP, Murff RT, Lynch DM, Odom RD. Mechanical treatment of plantar fasciitis. A prospective study. J Am Podiatr Med Assoc. 2001;91(2):55-62. PubMed ID: 11266478 doi:10.7547/87507315-91-2-55
29. Oliveira HAV, Jones A, Moreira E, Jennings F, Natour J. Effectiveness of total contact insoles in patients with plantar fasciitis. $J$ Rheumatol. 2015;42(5):870-878. PubMed ID: 25774062 doi:10. 3899/jrheum. 140429

30. Pfeffer G, Bacchetti P, Deland J, et al. Comparison of custom and prefabricated orthoses in the initial treatment of proximal plantar fasciitis. Foot ankle Int. 1999;20(4):214-221. PubMed ID: 10229276 doi:10.1177/107110079902000402

31. Powell M, Post WR, Keener J, Wearden S. Effective treatment of chronic plantar fasciitis with dorsiflexion night splints: a crossover prospective randomized outcome study. Foot ankle Int. 1998;19(1): 10-18. PubMed ID: 9462907 doi:10.1177/107110079801900103

32. Attard J, Singh D. A comparison of two night ankle-foot orthoses used in the treatment of inferior heel pain: a preliminary investigation. Foot Ankle Surg. 2012;18(2):108-110. PubMed ID: 22443996 doi:10.1016/j.fas.2011.03.011

33. Probe RA, Baca M, Adams R, Preece C. Night splint treatment for plantar fasciitis. A prospective randomized study. Clin Orthop Relat Res. 1999;368:190-195. doi:10.1097/00003086-199911000-00023

34. Radford JA, Landorf KB, Buchbinder R, Cook C. Effectiveness of low-dye taping for the short-term treatment of plantar heel pain: a randomised trial. BMC Musculoskelet Disord. 2006;7:64. PubMed ID: 16895612 doi:10.1186/1471-2474-7-64

35. Ring K, Otter S. Clinical efficacy and cost-effectiveness of bespoke and prefabricated foot orthoses for plantar heel pain: a prospective cohort study. Musculoskeletal Care. 2014;12(1):1-10. PubMed ID: 23801649 doi: $10.1002 / \mathrm{msc} .1053$

36. Roos E, Engstrom M, Soderberg B. Foot orthoses for the treatment of plantar fasciitis. Foot Ankle Int. 2006;27(8):606-611. PubMed ID: 16919213 doi:10.1177/107110070602700807

37. Ryan M, Fraser S, McDonald K, Taunton J. Examining the degree of pain reduction using a multielement exercise model with a conventional training shoe versus an ultraflexible training shoe for treating plantar fasciitis. Phys Sportsmed. 2009;37(4):68-74. PubMed ID: 20048543 doi:10.3810/psm.2009.12.1744

38. Sharma NK, Loudon JK. Static progressive stretch brace as a treatment of pain and functional limitations associated with plantar fasciitis: a pilot study. Foot Ankle Spec. 2010;3(3):117-124. PubMed ID: 20508011 doi:10.1177/1938640010365183

39. Sheridan L, Lopez A, Perez A, John MM, Willis FB, Shanmugam R. Plantar fasciopathy treated with dynamic splinting: a randomized controlled trial. J Am Podiatr Med Assoc. 2010;100(3):161-165. PubMed ID: 20479445 doi:10.7547/1000161

40. Tsai C, Chang W, Lee J. Effects of short-term treatment with kinesiotaping for plantar fasciitis. J Musculoskelet Pain. 2010; 18(1):71-80. doi:10.3109/10582450903495882

41. Turlik MA, Donatelli TJ, Veremis MG. A comparison of shoe inserts in relieving mechanical heel pain. Foot. 1999;9(2):84-87. doi:10. 1054/foot.1999.0522

42. Vicenzino B, McPoil TG, Stephenson A, Paul SK. Orthosis-shaped sandals are as efficacious as in-shoe orthoses and better than flat sandals for plantar heel pain: a randomized control trial. PLOS ONE. 2015;10(12):e0142789. PubMed ID: 26669302 doi:10.1371/journal. pone.0142789

43. Baldassin V, Gomes CR, Beraldo PS. Effectiveness of prefabricated and customized foot orthoses made from low-cost foam for noncomplicated plantar fasciitis: a randomized controlled trial. Arch Phys Med Rehabil. 2009;90(4):701-706. PubMed ID: 19345789 doi:10. 1016/j.apmr.2008.11.002

44. Walther M, Kratschmer B, Verschl J, et al. Effect of different orthotic concepts as first line treatment of plantar fasciitis. Foot Ankle Surg. 
2013;19(2):103-107. PubMed ID: 23548451 doi:10.1016/j.fas.2012. 12.008

45. Wheeler PC. The addition of a tension night splint to a structured home rehabilitation programme in patients with chronic plantar fasciitis does not lead to significant additional benefits in either pain, function or flexibility: a single-blinded randomised controlled trial. BMJ Open Sport Exerc Med. 2017;3(1):e000234. PubMed ID: 29259809 doi:10.1136/bmjsem-2017-000234

46. Wrobel JS, Fleischer AE, Crews RT, Jarrett B, Najafi B. A randomized controlled trial of custom foot orthoses for the treatment of plantar heel pain. J Am Podiatr Med Assoc. 2015;105(4):281-294. PubMed ID: 25941995 doi:10.7547/13-122.1

47. Batt ME, Tandji JL, Skattum N. Plantar fasciitis: a prospective randomized clinical trial of the tension night splint. Clin Sports Med. 1996;6(103):158-162. doi:10.1097/00042752-199607000-00004

48. Chia KK, Suresh S, Kuah A, Ong JL, Phua JM, Seah AL. Comparative trial of the foot pressure patterns between corrective orthotics, formthotics, bone spur pads and flat insoles in patients with chronic plantar fasciitis. Ann Acad Med Singapore. 2009;38(10):869-875. PubMed ID: 19890578

49. Dimou ES, Brantingham JW, Wood T. A randomized, controlled trial (with blinded observer) of chiropractic manipulation and Achilles stretching vs orthotics for the treatment of plantar fasciitis. $J \mathrm{Am}$ Chiropr Assoc. 2004;41(9):32-42.

50. Ferguson H, Raskowsky M, Blake RL, Denton JA. TL-61 versus Rohadur orthoses in heel spur syndrome. J Am Podiatr Med Assoc. 1991; 81(8):439-442. PubMed ID: 1920106 doi:10.7547/87507315-81-8-439

51. Fong DT, Pang KY, Chung MM, Hung AS, Chan K. Evaluation of combined prescription of rocker sole shoes and custom-made foot orthoses for the treatment of plantar fasciitis. Clin Biomech. 2012; 27(10):1072-1077. doi:10.1016/j.clinbiomech.2012.08.003

52. Hyland MR, Webber-Gaffney A, Cohen L, Lichtman PT. Randomized controlled trial of calcaneal taping, sham taping, and plantar fascia stretching for the short-term management of plantar heel pain. J Orthop Sports Phys Ther. 2006;36(6):364-371. PubMed ID: 16776486 doi:10.2519/jospt.2006.2078

53. Abd El Salam MS, Abd Elhafz YN. Low-dye taping versus medial arch support in managing pain and pain-related disability in patients with plantar fasciitis. Foot Ankle Spec. 2011;4(2):86-91. PubMed ID: 21123667 doi:10.1177/1938640010387416

54. Bonanno DR, Landorf KB, Menz HB. Pressure-relieving properties of various shoe inserts in older people with plantar heel pain. Gait Posture. 2011;33(3):385-389. PubMed ID: 21256025 doi:10.1016/j. gaitpost.2010.12.009

55. Mehta S, Basu S, Palekar TJ, Dave N. Effect of kinesio taping versus mulligan taping in treatment of heel pain. Int J Pharma Bio Sci. 2017;8(3):377-386. doi:10.22376/ijpbs.2017.8.3.b377-386

56. Ordahan B, Türkoğlu G, Karahan AY, Akkurt HE. Extracorporeal shockwave therapy versus kinesiology taping in the management of plantar fasciitis: a randomized clinical trial. Arch Rheumatol. 2017;32(3):227-233. PubMed ID: 30375530 doi:10.5606/ ArchRheumatol.2017.6059

57. Park C, Lee S, Kim S, Hwangbo G. The effects of the application of low-dye taping on paretic side plantar pressure among patients with plantar fasciitis. J Phys Ther Sci. 2015;27(11):3555-3557. PubMed ID: 26696737 doi:10.1589/jpts.27.3555

58. Park C, Lee S, Lim D-Y, Yi C, Kim JH, Jeon C. Effects of the application of low-dye taping on the pain and stability of patients with plantar fasciitis. J Phys Ther Sci. 2015;27(8):2491-2493. PubMed ID: 26355306 doi:10.1589/jpts.27.2491
59. Rome K, Gray J, Stewart F, Hannant SC, Callaghan D, Hubble J. Evaluating the clinical effectiveness and cost-effectiveness of foot orthoses in the treatment of plantar heel pain: a feasibility study. $\mathrm{J} \mathrm{Am}$ Podiatr Med Assoc. 2004;94(3):229-238. PubMed ID: 15153583 doi: $10.7547 / 0940229$

60. Van Lunen B, Cortes N, Andrus T, Walker M, Pasquale M, Onate J. Immediate effects of a heel-pain orthosis and an augmented low-dye taping on plantar pressures and pain in subjects with plantar fasciitis. Clin J Sport Med. 2011;21(6):474-479. PubMed ID: 22011796 doi:10.1097/JSM.0b013e3182340199

61. Van Tonder T, Allison GT, Hopper D, Grisbrook TL. Multidimensional impact of low-dye taping on low-load hopping in individuals with and without plantar fasciitis. Phys Ther Sport. 2018;29:43-49. PubMed ID: 29245027 doi:10.1016/j.ptsp.2017.11.001

62. Yucel U, Kucuksen S, Cingoz HT, et al. Full-length silicone insoles versus ultrasound-guided corticosteroid injection in the management of plantar fasciitis: a randomized clinical trial. Prosthet Orthot Int. 2013; 37(6):471-476. PubMed ID: 23471226 doi:10.1177/0309364613478328

63. Landorf KB, Radford JA. Minimal important difference: values for the foot health status questionnaire, foot function index and visual analogue scale. Foot. 2008;18(1):15-19. doi:10.1016/j.foot.2007.06.006

64. Radford JA, Burns J, Buchbinder R, Landorf KB, Cook C. The effect of low-dye taping on kinematic, kinetic, and electromyographic variables: a systematic review. J Orthop Sports Phys Ther. 2006;36(4): 232-241. PubMed ID: 16676873 doi:10.2519/jospt.2006.36.4.232

65. Kogler GF, Solomonidis SE, Paul JP. Biomechanics of longitudinal arch support mechanisms in foot orthoses and their effect on plantar aponeurosis strain. Clin Biomech. 1996;11(5):243-252. doi:10.1016/ 0268-0033(96)00019-8

66. Sobhani S, Zwerver J, van den Heuvel E, Postema K, Dekker R, Hijmans JM. Rocker shoes reduce Achilles tendon load in running and walking in patients with chronic Achilles tendinopathy. J Sci Med Sport. 2014;18(2):133-138. PubMed ID: 24636129 doi:10.1016/j. jsams.2014.02.008

67. Carlson RE, Fleming LL, Hutton WC. The biomechanical relationship between the tendoachilles, plantar fascia and metatarsophalangeal joint dorsiflexion angle. Foot ankle Int. 2000;21(1):18-25. PubMed ID: 10710257 doi:10.1177/107110070002100104

68. Cheung JTM, Zhang M, An KN. Effect of Achilles tendon loading on plantar fascia tension in the standing foot. Clin Biomech. 2006; 21(2):194-203. doi:10.1016/j.clinbiomech.2005.09.016

69. Erdemir A, Hamel AJ, Fauth AR, Piazza SJ, Sharkey NA. Dynamic loading of the plantar aponeurosis in walking. J Bone Joint Surg Am. 2004;86(3):546-552. PubMed ID: 14996881 doi:10.2106/00004623200403000-00013

70. Hutchins S, Bowker P, Geary N, Richards J. The biomechanics and clinical efficacy of footwear adapted with rocker profiles — evidence in the literature. Foot. 2009;19(3):165-170. doi:10.1016/j.foot.2009.01.001

71. Cheng HYK, Lin CL, Wang HW, Chou SW. Finite element analysis of plantar fascia under stretch-the relative contribution of windlass mechanism and Achilles tendon force. J Biomech. 2008;41(9):19371944. PubMed ID: 18502428 doi:10.1016/j.jbiomech.2008.03.028

72. Lin S, Chen CPC, Tang SFT, Wong AMK, Hsieh J, Chen W. Changes in windlass effect in response to different shoe and insole designs during walking. Gait Posture. 2013;37(2):235-241. PubMed ID: 22884544 doi:10.1016/j.gaitpost.2012.07.010

73. Bolgla LA, Malone TR. Plantar fasciitis and the windlass mechanism: a biomechanical link to clinical practice. J Athl Train. 2004;39(1):7782. PubMed ID: 16558682 


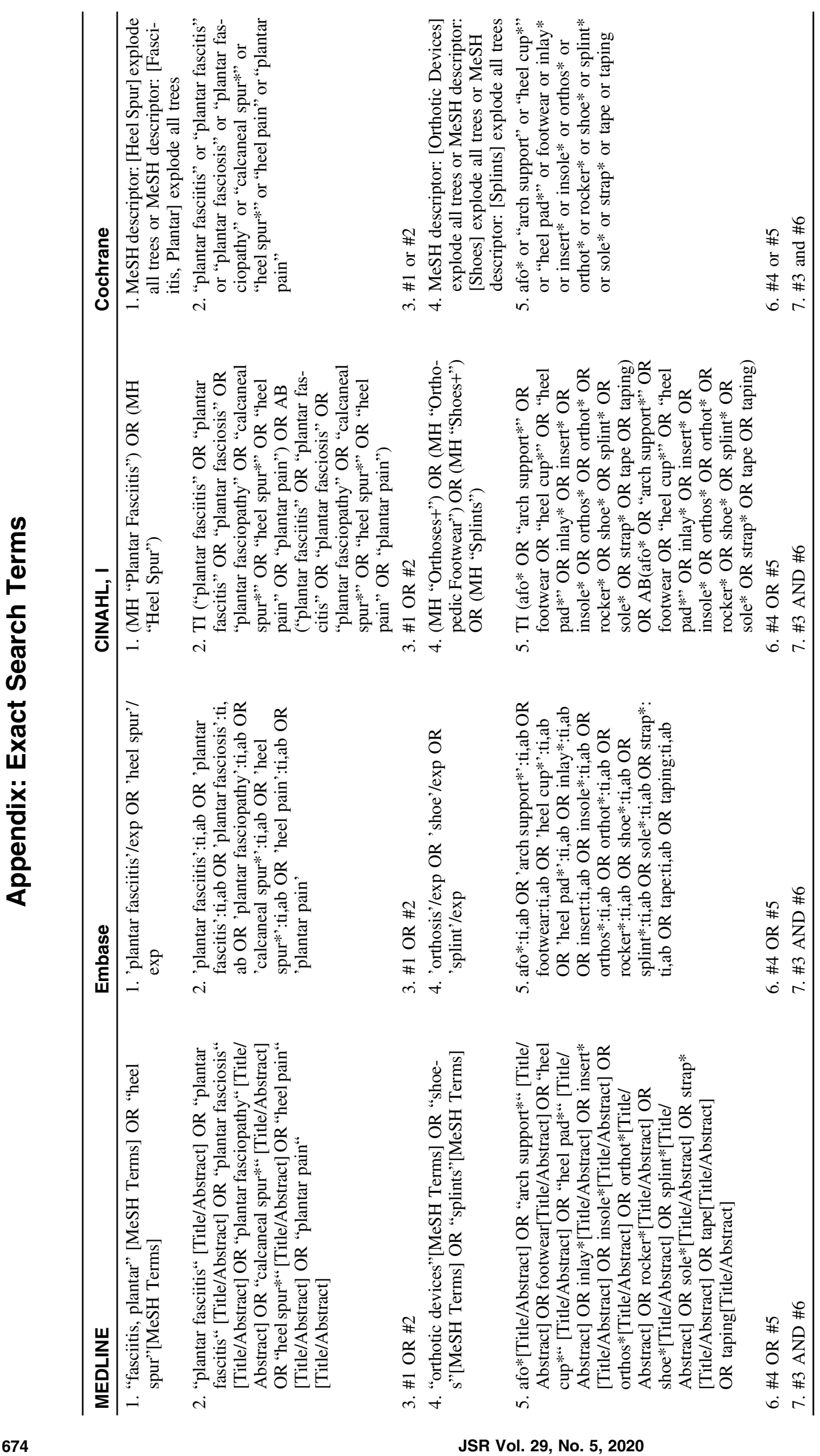

